\title{
Pattern of squint presentations in children in a tertiary institution in Western Nigeria
}

\author{
${ }^{1} \operatorname{Dr}$ (Mrs) O.T Bodunde, ${ }^{2} \operatorname{Dr}(\mathrm{Mrs})$ O.O Onabolu, ${ }^{3} \mathrm{Dr}$ (Mrs) V.O Fakolujo \\ Department Of Ophthalmology Olabisi Onabanjo University Teaching Hospital
}

\begin{abstract}
:
Background: Strabismus is a common condition in children, but there is paucity of studies done exclusively on it in Nigeria

Objective: To describe the pattern of presentation of strabismus among children presenting at the eye clinic, Olabisi Onabanjo University Teaching Hospital (OOUTH) Sagamu, Nigeria

Study design:- Retrospective.

Results: Strabismus constituted $0.01 \%$ of paediatric ophthalmic presentations to OOUTH over a 5year period of between January 2008 and December 2012.Age range is from 0.75-16years with a mean of 4.9years. The male female ratio was 1:2. Esotropia was the most common type of squint while the predominant refractive error was astigmatism. Only 5(31.3\%) of those whose onset was before 6months presented on or before 1 year There was very low uptake of treatment in these children.

Conclusion: The prevalence of strabismus was low, intensive health education of parents and teachers is necessary to encourage early presentation and good uptake of treatment as this has a direct effect on visual and cosmetic outcome.
\end{abstract}

Key words: Prevalence, Strabismus, Children, refractive error

\section{Introduction}

Squint or " crossed eye" is a relatively common condition worldwide especially among newborns. Horwood et al reported a prevalence of about $73 \%$ in one month old babies, reducing to $50 \%$ in two month old babies and virtually disappearing in normal four month olds ${ }^{1}$. The prevalence of squint in 5year olds is said to be about $5 \%^{2}$. A study done among primary school children in Ilorin, Nigeria recorded a prevalence of $0.14 \%^{3}$. Strabismus may have an adverse effect on family relationships ${ }^{4}$. In addition, delayed development (e.g., reaching milestones such as first walking and using single words) and difficulty with tasks involving visual perception have been found in young children with strabismus ${ }^{5,6}$. Young children with strabismus often develop amblyopia and impaired stereopsis. Early identification and treatment of strabismic children may prevent amblyopia ${ }^{7}$. The strabismus child with amblyopia has a significantly higher risk of becoming blind by losing vision in the non-amblyopic eye, due to trauma or disease ${ }^{8,9}$. In the developed countries, many parents notice squint early in their babies and present early to the ophthalmologists unlike in the developing countries. The uptake of treatment in the developed countries is also much higher than in the developing countries. This study was carried out to review the pattern of presentation of squint with uptake of treatment among paediatric patients presenting at Olabisi Onabanjo University Teaching hospital (OOUTH).

\section{Materials And Method}

This is a retrospective study, and was carried out by reviewing the records of all patients presenting at OOUTH from January 2008 to December 2012, a 5year period. All the case notes of paediatric patients ages 0$16 y e a r s$ diagnosed as having squint were retrieved and analyzed. The demographic data, history of prematurity, history of asphyxia, family history of squint, age of onset ,type of squint, and cycloplegic refraction with atropine, were retrieved from the case notes. Data was imputed into personal computer and analysed using SPSS version 16.

\section{Result}

A total of 20,463 patients were seen in the eye clinic during the study period. Children constituted $3197(15.6 \%)$ of the total number of patients seen. There were 1687(52.8\%) males and 1510(47.2\%) females. Thirty eight $(0.01 \%)$ patients presented with squint but only twenty-two (22) case notes were available for analyses constituting fifty seven point nine percent $(57.9 \%)$ of the patients presenting with squint. There were 7 males and 15 females (Table 1) with a male female ratio of 1:2.1. Nineteen (86.4\%) were esotropic, 3 (13.6\%) were exotropic (Table 2). The age range at presentation is from 0.75 to 16 years with a mean of 4.9 years \pm 4.13 years. Sixteen $(72.7 \%)$ of the squint were noticed before six (6) months of life however none presented at that 
age. Only $5(31.3 \%)$ of those whose onset was before 6 months presented on or before 1 year. $2(12.5 \%)$ actually presented after $10 y e a r s$ of age. Only one patient had history of low birth weight being a second twin. Six (27.3\%) had positive history of birth asphyxia while only $2(9.1 \%)$ had positive family history of squint. Four (18.2\%) patients had associated nystagmus. Only 11(50\%) patient came for cycloplegic refraction. Of these 4(36.4\%) had hypermetropia of more than +2.00DS, 3(27.3\%) had myopia of any degree while $10(90.9 \%)$ had astigmatism of greater than 0.50DS. One child with lateral rectus palsy had an intra -abdominal neoplasm for which a metastasis to the orbit was entertained while another child with exotropia had hydrocephalus for which he had a shunt procedure at another tertiary center in a nearby state. Spectacles were prescribed for those with significant refractive error but only 2 patients actually obtained their spectacles .However none of them returned for follow up.

\section{Discussion}

Squint is a common condition among children, it is said to occur in 1 in 50 children ${ }^{10}$. That there was a female preponderance in this study is something of note since it had never been reported to be commoner in females than males. This could be attributed to the impact of squint on the physical appearance of a female child with attendant psychological effect in future or the small sample size. Esotropia was the commonest type of squint like in many other similar reports ${ }^{1,11,12}$ being the most common childhood squint. Though genetic predisposition has been associated with squint development, we didn't find much evidence of this in this study as only one of the patients was a twin and the first twin did not have squint. Only two patients had family history of squint. Siblings of a child with a convergent squint have a doubled risk of developing a similar condition ${ }^{1}$.

Though $70 \%$ of the squints were noticed before six months of age only $5(31.3 \%)$ presented before age 1 year. This delay in management will have a significant impact on the outcome especially with two of them presenting after age 10years. These children may have problem with stereopsis and would have developed significant amblyopia. Studies have suggested that both the duration of ocular misalignment and the age at which the eyes are straightened are of prognostic importance: they correlate not only with improved stereoacuity outcome but also with improved stability of the long-term eye position and a lesser need for corrective surgery at an older age ${ }^{13,14}$. Stereoacuity develops between three and five months of age and matures to a near adult level during the first two years of life. Surgery before the age of two years-possibly within the first six to twelve months of life - is now believed to maximize the chance of a good outcome ${ }^{14}$.

The predisposing factors to the development of squint such as prematurity, family history and cerebral palsy were not prominent in this study as only two patients have positive family history of squint and six history of birth asphyxia. This could be because of the small sample size in this study. That fact that one child had hydrocephalus and another with abdominal mass is of note because a high index if suspicion is necessary especially in this environment where good history are not always available in most cases.

Astigmatism (90.9\%) was found to be the commonest refractive error, followed by hypermetropia (36.4\%) contrary to findings of Azonobi et al ${ }^{15}$ though similar to their findings astigmatism was more common in children having hypermertopia.

Correction of refractive error is the most important first treatment for squint, however only 11(45. 5) waited for refraction and only two patients obtained corrective spectacle. This is probably related to the myth in this part of the world that squint corrects itself with age, it has been discovered that even health workers advise that squint improves spontaneously on its own. This will also explain the high defaulter rate. There is need for intensive health education of parents, and other medical personnel's on the need to identify and treat squint as early as possible.

\section{Conclusion}

We conclude that squint cases usually present late to the hospital and uptake of treatment is very poor. An intensive health education need to be embarked upon via media, schools, health centers to correct the myth of this society that squint will be corrected spontaneously with age and that early treatment is essential for a good visual outcome.

\section{References}

[1]. Horwood A.M, Riddell P.M.Can misalignments in typical infants be used as a model for infantile esotropia? Invest Ophthalmol Vis Sci.2004 Feb; 45(2):714-20

[2]. Ocampo VVD et al, Infantile Esotropia, Medscape, May 2012

[3]. Azonobi IR ${ }^{1}$, Olatunji FO, Addo J.Prevalence and pattern of strabismus in Ilorin. Am J Ophthalmol. 2007 Sep;144(3):465-7

[4]. Akag A.P, Cakaloz B, Berk A.T, Pasa E. Psychosocial aspects of Mothers in Children with Strabismus. JAAPOS 2005;9:268-73

[5]. Prosser P.C.Infantle development: strabismic and normal children compared .Ophthalmic Optician 1979; 19:681-3

[6]. Tonge B.J, Lipton G.L, Crawford G. Psychological and educational correlates of strabismus in school children. Aust N Z J Psychiatry $1984 ; 18: 71-7$

[7]. Robaei D, Rose KA, kifley A,et al. Factors associated with childhood strabismus: findings from a population-based study. Ophthalmology 2006; 113:1146-53 
[8]. Tomilla V, Tarkkanen A. Incidence of loss of vision in the healthy eye in amblyopia.Br J Ophthalmol 1981;65:575-7

[9]. van Leeuwen R, Eijkemins MJ,Vingerling JR,et al. Risk of bilateral visual impairment in individual with amblyopia: the Rotterdam study.Br J Ophthalmol 2007;91:1450-1

[10]. Elston J. Concomitant strabismus. In: Taylor D, ed. Paediatric Ophthalmology. Oxford: Blackwell Science, 1997.

[11]. Louwagie CR, Diehl NN, Greenberg AE, et al; Is the incidence of infantile esotropia declining?: a population-based study from Arch Ophthalmol. 2009 Feb;127(2):200-3.

[12]. Chimonidou E, Palimeris G, Kolopoulos J, Verlissaropoulos P. Family distribution of concomitant squint in Greece. Br J Ophthalmol 1997;61:27-29

[13]. Neepa T ,Arthur L R, Federico GV, V-Pattern Esotropia and Exotropia, Mescape, Dec 2011

[14]. Rutstein R et al, Strabismus: Esotropia and Exotropia, American Optometric Association, 2010

[15]. 15 Azonobi R, Olatunji F, Adido J.Refractive Error among strabismic children in Ilorin, Nigeria. West Afr J Med. 2009 JulAug; 28(4):253-6.

Table 1: Type Of Squints Children Attending The Eye Clinic At Oouth,Sagamu

\begin{tabular}{lc}
\hline SQUINT & Number $(\%)$ \\
\hline ESOTROPIA & $19(86.4)$ \\
EXOTROPIA & $3(13.6)$
\end{tabular}

Total $22(\mathbf{1 0 0 . 0})$

Table 2: Type Of Refractive Error Among Children With Squint Attending The Eye Clinic At Oouth, Sagamu

\begin{tabular}{lc}
\hline ERROR & Number (\%) \\
\hline Hypermetropia $>2.0 D S$ & $4(36.4)$ \\
Myopia(any degree) & $3(27.3)$ \\
Astigmatism $>0.5 D S$ & $10(90.9)$ \\
Anisometropia $>1.0 D S$ & NIL
\end{tabular}

Total $22(\mathbf{1 0 0 . 0 )}$

